\title{
Association of cardiovascular metabolic risk factor measurements with psychiatric readmission among in-hospital patients with severe mental illness: a retrospective study
}

\author{
Xiao Wei Tan ${ }^{1 *}$, Christopher Yi Wen Chan ${ }^{1}$, Alvin Wai Mum Lum², Eng Sing Lee ${ }^{3,4}$, Yee Ming Mok ${ }^{1,5}$,
} Daniel Shuen Sheng Fung ${ }^{1,4}$ and Phern Chern Tor ${ }^{1,5}$

\begin{abstract}
Background: Patients with severe mental illness (SMI) and comorbid physical conditions were often associated with higher risks of mortality and hospital readmission. In this study, we aim to examine the association of cardiovascular metabolic risk factor measurements with risks of psychiatric readmissions among in-hospital patients with severe mental illness (SMI).

Methods: We collected the longitudinal information of laboratory investigations, blood pressure and body mass index (BMI) among in-hospital patients who had been diagnosed with schizophrenia, major depression disorder or bipolar disorder and with comorbid diagnosis of hypertension, hyperlipidemia or diabetes from Jan 2014 to Jan 2019. The primary outcome was time to first psychiatric readmission. Cox proportional hazard model was utilized to calculate the hazard risks (HR) of cardiovascular metabolic risk factors with psychiatric readmission.

Results: A total of 5,256 patients were included in the analysis. Compared to patients with normal blood parameters, patients with aberrant tests of high-density dyslipidemia (HDL) and diastolic blood pressure (DBP) during in-hospitalization period were associated with higher risks to first psychiatric readmission [ HR (Hazard Ratio), 1.37 95\% Confidence interval (Cl), 1.03-1.83 for HDL and HR, 1.32 (95\% Cl, 1.04-1.67])for DBP]. Compared to patients with optimal monitoring, patients with suboptimal monitoring of blood lipids and blood pressure during in-hospitalization period or recommended window period of cardiovascular disease (CVD) risk management were associated with higher risks to first psychiatric readmission.
\end{abstract}

Conclusions: Aberrant cardiovascular metabolic blood test and blood pressure and missing measurements among in-hospital patients with SMI were associated with increased risks of psychiatric readmissions. This calls for more active screening and monitoring of CVD risk factors for those in-hospital patients in need.

Keywords: Severe mental illness, Cardiovascular disease, Mental-physical comorbidity, Psychiatric readmission, Metabolic risk factor

\footnotetext{
*Correspondence: xiaowei_tan@imh.com.sg

1 Department of Mood and Anxiety, Institute of Mental Health, Buangkok Green Medical Park, 10 Buangkok View, Singapore 539747, Singapore Full list of author information is available at the end of the article
}

\section{Introduction}

Severe mental illness (SMI) including schizophrenia, major depression disorder (MDD) and bipolar disorder have heavy global burdens of illness due to poor prognosis, [1-3] long-term disability, [4] increased sickness 
absence [4] and repeated hospitalization [5]. Patients with SMI were often associated with high risks of comorbid physical illness including cardiovascular disease (CVD) or diabetes mellitus (DM), which resulted in a significant higher incidence of adverse cardiovascular events and a shortened life span of 10 to 20 years compared with the general population [6-9]. This mortality gap has widened in recent years, even in countries where the quality of the health care system is generally acknowledged to be good [10-13]. The modifiable risk factors for comorbid CVDs include smoking, diet, exercise, obesity, hypertension, elevated blood glucose and dyslipidemia [14]. Concurrent elevation of these risk factors is more common among patients with SMI compared with the general population [15]. Developing metabolic syndrome is also a common side effect due to either typical or atypical usage of antipsychotic medications [16-18].

Various educational modules, monitoring and treatment guidelines as well as recommendations at the health care institutions and individual level have been discussed to guide the management of cardiovascular metabolic risks among patients with SMI [19-22]. Patients need be assessed at regular intervals for personal and family history of DM, hypertension or CVD, smoking, physical activities, diet, lipid profile, fasting blood glucose (FGlu), Hemoglobin A1c (HbA1C), blood pressure (BP) and body mass index (BMI). Patients are recommended to be assessed with increased frequency if they are being treated with antipsychotic medication [23, 24]. Although most of the psychiatrists and medical professionals within mental health hospitals are aware of the high risk of comorbid metabolic syndromes for those patients with SMI, evidence exists about the suboptimal management of comorbid metabolic syndromes among patients with SMI due to various reasons such as the focused management of psychiatric symptoms and adherence to psychiatric treatment $[25,26]$. In some countries including Singapore, patients with SMI in Singapore were referred to family physicians or other general hospitals for further treatment once they have been diagnosed with comorbid metabolic syndromes [27-29].

Substantial evidence has demonstrated that patients with mental illnesses are at a higher risk for hospital readmission due to poor physical health conditions compared to those without mental illness [30-32]. Large body of studies also supported the hypothesis that patients with mental illness are at increased risk of psychiatric readmission if they had co-occurring medical condition [33, 34]. However, it remains unclear whether in-hospital measurement of cardiovascular risk factors such as blood test of metabolic risk factors and blood pressure during the period of psychiatric admission have essential influence on the subsequent psychiatric readmission. To address this gap, we proposed a retrospective study using electronic health records (EHRs) of in-hospital patients with diagnosis of SMI and with comorbid DM, hyperlipidemia or hypertension who requires more intensive attention of CVD risk factor management than those patients without comorbid DM, hyperlipidemia or hypertension. We hypothesize that poorer control of the cardiovascular metabolic risk factors for in-hospital patients with SMI are associated with higher risks of psychiatric readmission.

\section{Methods}

\section{Design, settings and study sample}

This is a retrospective cohort study. We collected the data from EHRs of patients in the Institute of Mental Health (IMH) from 01 January 2014 to 31 January 2019. The inclusion criteria were 1) Patients with at least one primary diagnosis of schizophrenia, major depression disorder or bipolar disorder. The details of the diagnosing code and subtypes of diagnosis are listed in Supplementary table 1. 2) Patients with at least one psychiatric admission during the study period. 3) Patients with history of DM, hyperlipidemia or hypertension before the first admission. The inclusion criteria were only applied for patients with acute admissions and all forensic cases were excluded. All methods in this study were carried out in accordance with guidelines and regulations stated in the local ethnic committee-Domain Specific Review Board (DSRB) Investigator's manual with patient's informed consent being waived.

\section{Data collection}

We extracted relevant patient information from electronic medical records using a data collection form. This included socio-demographic information such as age, gender and ethnicity; clinical information such as medical history, diagnosis, hospitalization admission date, admission type, admission diagnosis, discharge date, discharge diagnosis, medicine prescription including antipsychotics, antidepressants, mood stabilizers, drugs that control blood pressure, blood glucose and lipids, date of psychotherapies and electroconvulsive therapies (ECT), blood tests including high density lipoprotein (HDL), low density lipoprotein (LDL), fasting glucose and HbA1C, blood pressure and BMI. For patients with multiple records of blood tests and parameters, we chose to present the result closest to the first discharge date.

\section{Definitions}

We obtained the blood tests' results from the laboratory information systems and the records of BP and BMI from the patients' case notes. According to the current practicing guidelines in National Healthcare Group in 
Singapore [35], among patients with a diagnosis of DM, $\mathrm{HDL} \geq 1.0 \mathrm{mmol} / \mathrm{l}, \mathrm{LDL}<2.6 \mathrm{mmol} / \mathrm{L}, \mathrm{FGlu}<7.0 \mathrm{mg} / \mathrm{L}$, $\mathrm{HbA} 1 \mathrm{C}<7.0 \%, \quad \mathrm{SBP}<140 \mathrm{mmHg}, \quad \mathrm{DBP}<80 \mathrm{mmHg}$, and $\mathrm{BMI}<23 \mathrm{~kg} / \mathrm{m}^{2}$ were considered as normal testing of their CVD risk factors. Among patients without a comorbid diagnosis of DM (i. e. hyperlipidemia or hypertension), $\mathrm{HDL} \geq 1.0 \mathrm{mmol} / \mathrm{l}, \mathrm{LDL}<4.1 \mathrm{mmol} / \mathrm{L}$, FGlu $<6.0 \mathrm{mg} / \mathrm{L}, \quad \mathrm{HbA} 1 \mathrm{C}<6.0 \%, \quad \mathrm{SBP}<140 \mathrm{mmHg}$, $\mathrm{DBP}<90 \mathrm{mmHg}$ and $\mathrm{BMI}<23 \mathrm{~kg} / \mathrm{m}^{2}$ were considered as normal testing of their cardiovascular metabolic risk factors. Otherwise, the risk factors were considered as "abnormal test". Suboptimal monitoring of CVD risk factors was defined as without performing the above tests. Optimal monitoring of CVD risk factors was defined as with performing the above tests regardless of the testing outcome.

Considering some patients were lacking records of blood test or screening of BP and BMI after admission, we also utilized the 2011 European guideline of metabolic risk factor monitoring by De Hert, M. et al. [24] to pick up patients' records during a window period of CVD risk factor screening before the index hospitalization, i.e. within one year for lipid profile, FGlu, HbA1C and within three months for BP and BMI.

\section{Statistical analysis}

We used descriptive statistics for sociodemographic and clinical characteristics. Numerical variables were presented as mean \pm standard deviation (SD) and categorical variables were presented as count and percentage (\%). Cox regression model (proportional hazard model) was utilized to calculate the association between risk predictors and clinical outcomes. The major risk predictors (variables of interest) were blood tests, BP and BMI which were dichotomized into "normal tests vs abnormal test" or "optimal monitoring vs suboptimal monitoring" as defined previously. For risk prediction only patients' information before and during first admission were included as predictor variables. The outcome was time to the first readmission. Calculated hazard risks (HRs) were adjusted for patients' socio-demographics and clinical characteristics including primary diagnosis, admission type, medicine prescription, behavior therapy and ECT therapy during first hospitalization period. Statistical significance was accepted at $p<0.05$ level for all tests. Data were analyzed by SAS 6.0 and STATA (version 15.0).

\section{Results}

A total of 5,256 patients were included in this study and their socio-demographics are presented in Table 1 . The mean age was $56 \pm 14$ (mean \pm SD) years and $47.3 \%$ were female. $73.6 \%$ of recruited patients were Chinese, $11.4 \%$ were Malay and $10.9 \%$ were Indian. $64.2 \%$ of the
Table 1 Patients' socio-demographics and clinical characteristics $(n=5256)$

\begin{tabular}{|c|c|c|c|}
\hline \multicolumn{2}{|l|}{ Patient characteristics } & \multirow{2}{*}{$\begin{array}{l}\text { Count } \\
56 \pm 14\end{array}$} & \multirow[t]{2}{*}{$\%$} \\
\hline Age $($ mean $\pm S D)$ & & & \\
\hline \multirow[t]{2}{*}{ Gender } & Female & 2485 & 47.3 \\
\hline & Male & 2771 & 52.7 \\
\hline \multirow[t]{5}{*}{ Ethnicities } & Chinese & 3870 & 73.6 \\
\hline & Malay & 600 & 11.4 \\
\hline & Indian & 575 & 10.9 \\
\hline & Caucasian & 21 & 0.4 \\
\hline & Others & 190 & 3.6 \\
\hline \multirow[t]{7}{*}{ Religion } & Buddhism & 366 & 7 \\
\hline & Christine & 221 & 4.2 \\
\hline & Hinduism & 99 & 1.9 \\
\hline & Islam & 243 & 4.6 \\
\hline & Taoism & 30 & 0.6 \\
\hline & Free thinker & 160 & 3 \\
\hline & No mapping & 4137 & 78.7 \\
\hline \multirow[t]{5}{*}{ Marital Status } & Married & 1515 & 28.8 \\
\hline & Divorced & 210 & 4 \\
\hline & Single & 1702 & 32.4 \\
\hline & Widowed & 52 & 1 \\
\hline & No mapping & 1777 & 33.8 \\
\hline \multirow[t]{5}{*}{ Primary diagnosis } & Schizophrenia & 3373 & 64.2 \\
\hline & Depression & 1349 & 25.7 \\
\hline & Bipolar disorder & 534 & 10.2 \\
\hline & Hypertension & 2539 & $48.3 \%$ \\
\hline & Diabetes & 3142 & $59.8 \%$ \\
\hline \multirow[t]{3}{*}{ Cardiovascular diagnosis } & Hyperlipidemia & 4221 & $80.3 \%$ \\
\hline & Any 2 combined & 1560 & $29.7 \%$ \\
\hline & Triple high & 1543 & $29.4 \%$ \\
\hline \multirow[t]{8}{*}{ Medicine prescription } & Antipsychotics & 3729 & 70.9 \\
\hline & Antidepressant & 2516 & 47.9 \\
\hline & Mood stabilizer & 3021 & 57.5 \\
\hline & CVD protection & 203 & 3.9 \\
\hline & Lowering blood glucose & 1013 & 19.3 \\
\hline & Lowering blood lipid & 2116 & 40.3 \\
\hline & Lowering blood pressure & 1367 & 26 \\
\hline & Others & 3921 & 74.6 \\
\hline \multirow[t]{4}{*}{ Behavior therapies } & Psychotherapy & 187 & 3.6 \\
\hline & $\begin{array}{l}\text { Structured educational } \\
\text { therapy }\end{array}$ & 1515 & 28.8 \\
\hline & Structured group therapy & 712 & 13.5 \\
\hline & $\begin{array}{l}\text { Structured recreational } \\
\text { therapy }\end{array}$ & 1828 & 34.8 \\
\hline Other treatment & Electroconvulsive therapy & 110 & 2.1 \\
\hline
\end{tabular}

$S D$ standard error, $C V D$ cardiovascular disease

patients were diagnosed with schizophrenia, $25.7 \%$ were diagnosed with major depression disorder and 10.2\% were diagnosed with bipolar disorder. There were 2539 
(48.3\%) patients with comorbid diagnosis of hypertension, 3142 (59.8\%) with comorbid DM and 4221 (80.3\%) with comorbid hyperlipidemia.

For blood tests during admission, HDL and LDL were performed for $16.8 \%$ and $16.1 \%$ of the total patients, FGlu for $14.7 \%$ of the total patients and $\mathrm{HbA} 1 \mathrm{C}$ for $7.3 \%$ of the total patients. For parameters, BP was recorded for $24.5 \%$ and BMI for $5.6 \%$ of the total patients (Fig. 1A). Within the recommended window period of CVD risk factor screening, $18.2 \%$ of total patients had blood test for HDL/ LDL, $16.3 \%$ for FGlu, 15.4\% for HbA1C, $85.8 \%$ for measurement of $\mathrm{BP}$ and $45.7 \%$ with measurement for BMI. (Fig. 1B).
During the in-hospitalization period, compared to patients with normal tests, patients with abnormal tests of HDL and DBP were associated with higher hazard risks of subsequent psychiatric readmission (adjusted HR, 1.37 [95\% CI, 1.03-1.83] for HDL and adjusted HR, 1.32 [95\% CI, 1.04-1.67] for DBP, Table 2). Compared to patients with optimal CVD risk factor monitoring during the hospitalization period, patients with suboptimal monitoring of HDL, LDL, FGlu, SBP, DBP and BMI were associated with higher hazard risks of subsequent psychiatric readmission (adjusted HR, 1.67 [95\% CI, 1.47-1.89] for HDL; adjusted HR, 1.68 [95\% CI, 1.48-1.91] for LDL; adjusted HR, 1.69 [95\% CI, 1.48-1.93] for FGlu; adjusted

\section{A Patients with blood test, BP and BMI measurement during in-hospitalization period \\ (total $\mathrm{n}=5256$ )}

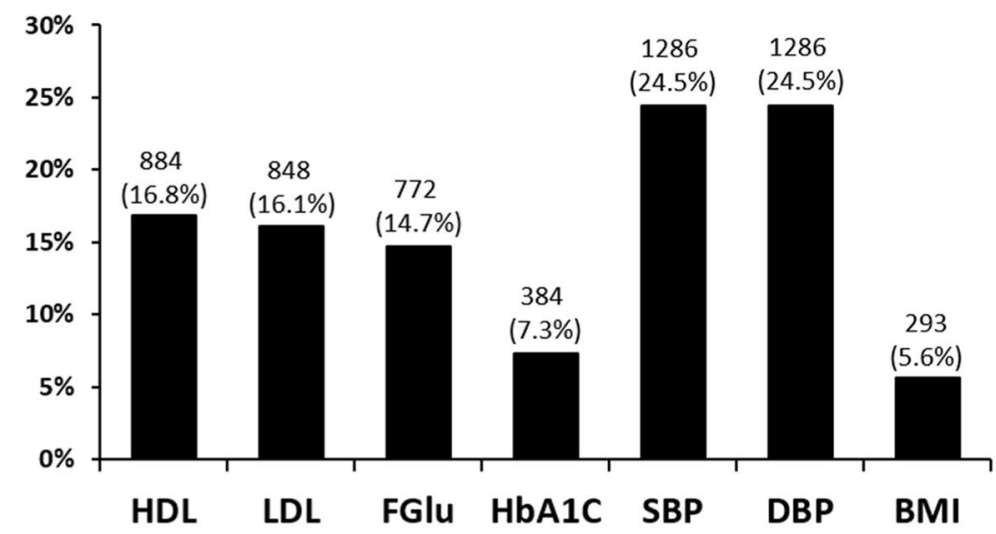

\section{B}

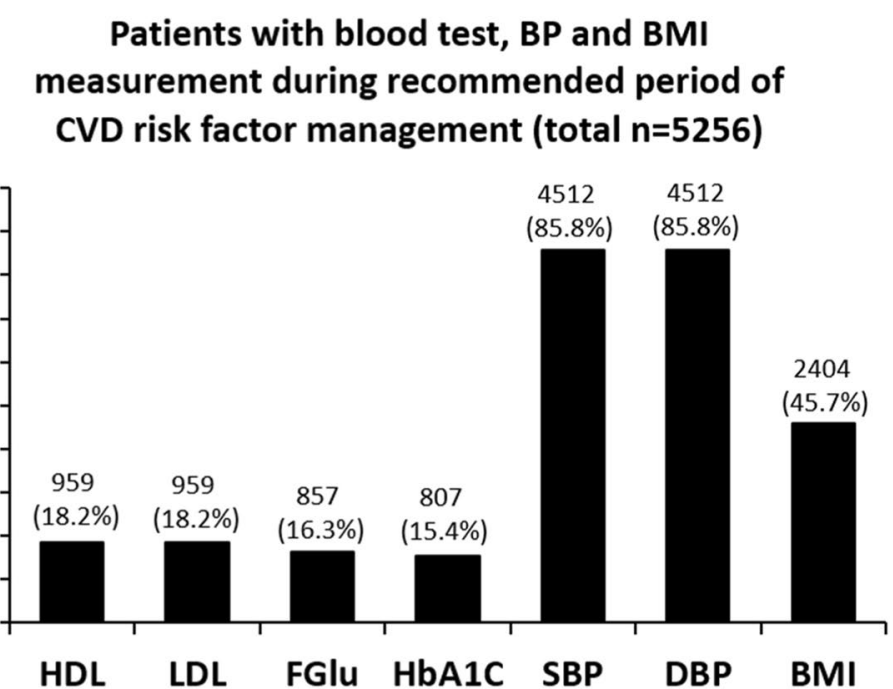

Fig. 1 Percentage of patients with blood test, BP measurement and BMI measurement during hospitalization period or recommended period of CVD risk factor management 


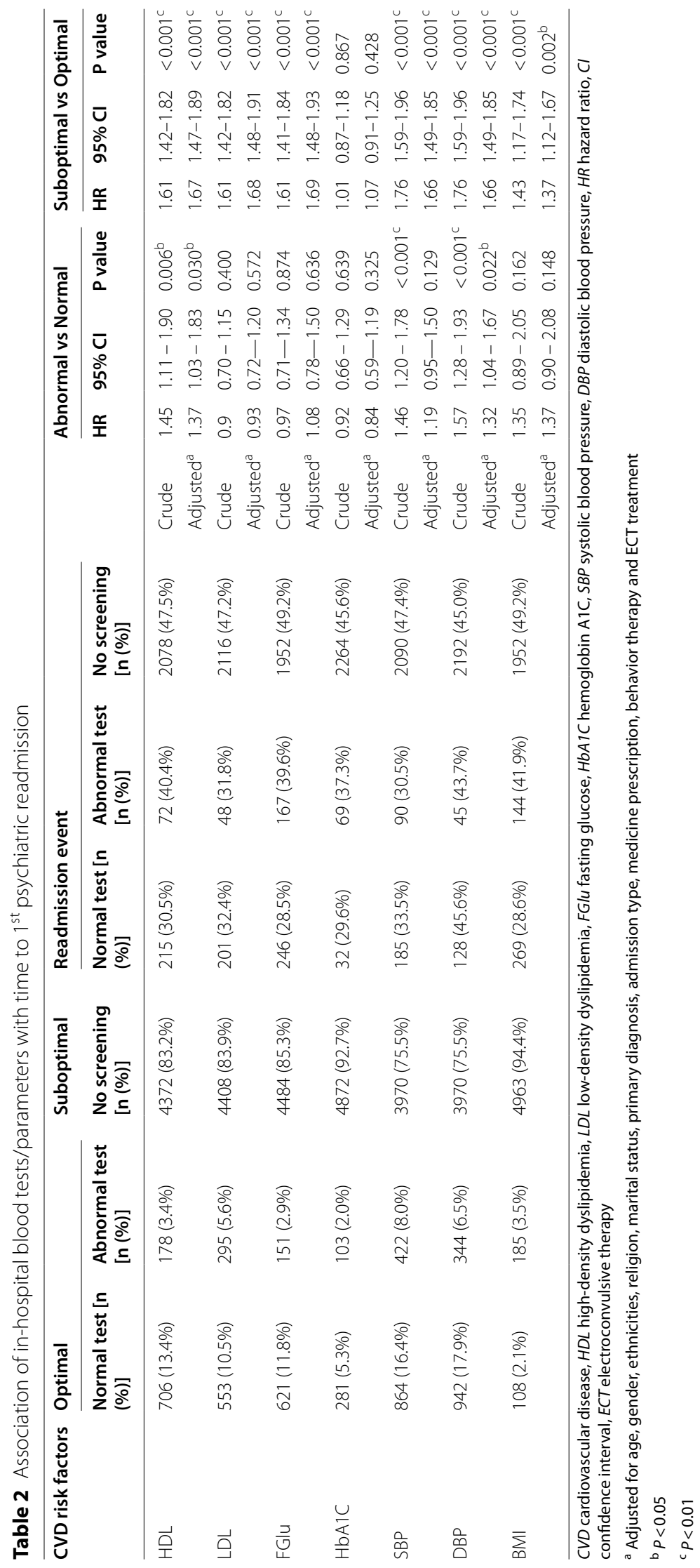


HR, 1.66 [95\% CI, 1.49-1.85] for SBP; adjusted HR, 1.66 [95\% CI, 1.49-1.85] for DBP and adjusted HR, 1.37 [95\% CI, 1.12-1.67] for BMI).

During the recommended period of CVD risk factor management, compared to patients with normal tests, patients with abnormal tests of $\mathrm{HbA1C}$ were associated with higher hazard risks of subsequent psychiatric readmission (adjusted HR, 12.2 [95\% CI, 2.55-58.38], Table 3). Compared to patients with optimal monitoring, patients with suboptimal monitoring of HDL, LDL, FGlu, SBP and DBP were associated with higher hazard risks of psychiatric readmission (adjusted HR, 1.74 [95\% CI, 1.54-1.97] for HDL; adjusted HR, 1.74 [95\% CI, 1.541.97] for LDL; adjusted HR, 1.75 [95\% CI, 1.54-1.99] for FGlu; adjusted HR, 2.07 [95\% CI, 1.87-2.30] for HDL and adjusted HR, 2.07 [95\% CI, 1.87-2.30] for DBP, Table 3).

\section{Discussion}

The key finding of this study is that among in-hospital patients with SMI, poor monitoring (missing screening) of metabolic risk factors was associated with higher risks of psychiatric readmission. i. e. a shorter time to psychiatric readmission. To our knowledge so far, this is the first study reporting the association of psychiatric in-hospital measurement of cardiovascular metabolic risk factors with psychiatric readmission.

The regular screening and management of metabolic risk factors is essential to decrease the incidence of adverse cardiovascular events and mortality among patients with SMI. In our study, large proportion of patients with SMI and with comorbid cardiovascular diseases did not receive screening of cholesterol, glucose, $\mathrm{BP}$ or BMI during in-hospitalization period or a relative longer recommended window period of screening. One possible reason is due to missing data entry. However, missing data is unlikely to completely account for the relatively large proportion of patients lacking CVDs risk factor measurement during in-hospital treatment period. Another possibility is that the treating psychiatrist in our hospital did not routinely screen the patients for comorbid metabolic biomarkers and this is not unusual. Previous studies reported that about a high percentage till $70 \%$ of patients taking secondary generation antipsychotics remained unscreened for risks factors of diabetes or dyslipidemia [36-38]. The barriers of screening were most likely due to various logistic reasons including the heavy burden of psychiatric symptoms, insufficient staff, wait times for medical follow-up and difficulties coordinating with off-campus physicians etc. [25, 26]. However, implementation of a complete set of metabolic risk factor screening for those patients with SMI and high risk of comorbid CVDs is feasible [39]. One effective tool for improving rates of screening is the adoption of an inhouse medical service from family physicians.

The adoption of in-house medical services was supported by several randomized clinical trials to screen and treat comorbid physical illness among patients with SMI, which proved to be effective in terms of the improvement of patient quality of life and a reduction of cardiovascular risks [40, 41]. However, we have known that large quantities of patients were absent from the follow-up appointment with on-site primary care physicians after being discharged from the mental hospital [29]. Further implementation measurements, therefore, are needed to reinforce the screening and subsequent treatment of cardiovascular metabolic risk factors by on-site family physicians within mental hospital.

Comorbid physical illness is one emerging risk factor for psychiatric readmission. Large number of studies has proven the high incidence of comorbid physical illness among patients with SMI. The association of physical conditions with psychiatric readmission can vary according to the nature of mental disorders, characteristics of study population, applied concept of comorbidity, and study protocol [34]. Reported from a study among patients with mental and/or substance use disorder (SUD), comorbid diagnosis of DM or hypertension was associated with increased risk of psychiatric readmission within 30 days after discharge [42]. Patients with SMI were also reported to have an increased risk of psychiatric readmission within seven years after discharge if they had higher Charlson comorbidity index scores [43]. In our study, instead of comparing the patients with and without history of comorbid physical illness, we examined the impact of in-hospital blood tests of CVD risk factors or BP on the risks of psychiatric readmission among patients with known history of CVDs.

We found that abnormal testing and the poor monitoring of CVD blood risk factors and BP were associated with higher risks of psychiatric readmission after adjustment for socio-demographics, drugs dispensed and other psychiatric treatment. Among the targeted CVD risk factors, blood lipids and blood pressure were significant contributors of these association as abnormal tests/suboptimal monitoring of HDL and DBP were consistently associated with increased risks of psychiatric readmission after adjustment for socio-demographics and other clinical characteristics. The central nervous system mechanisms of the action of these blood parameters or BP may account for the observed association between blood lipids or blood pressures and psychiatric readmission. Human studies have yielded promising results about the role of cholesterol or cholesterol-containing molecules in the prognosis of SMI. Although LDL is one of the major blood lipids screened by physicians to 


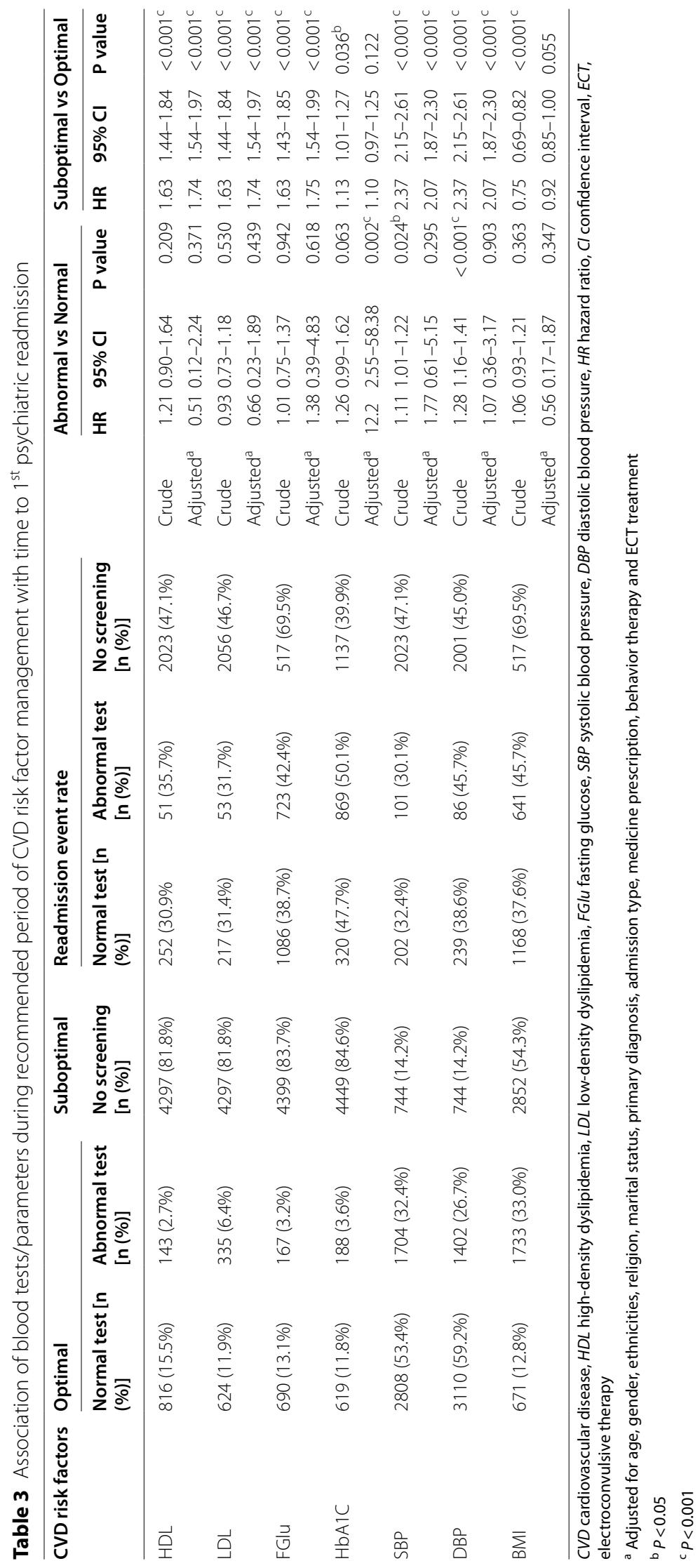


monitor the metabolic conditions, a considerable body of research has demonstrated that compared with healthy people, MDD patients including those protracted cases who lack remission often exhibit a decrease in HDL [44, 45]. Dyslipidemia and lower level of plasma HDL were also reported to be associated with acute-phase schizophrenia [46]. Another index of metabolic syndromes, BP, was proposed to explain the associations between psychopathology and CVDs among patients with depressive symptoms while the direction of those associations was contradictory [47-50] and may be confounded by the use of antidepressants [51]. Pulse pressure was reported to be significantly correlated with cognitive impairment, which was a core feature of schizophrenia [52]. Therefore, our examinations of the relationship between blood lipids/ blood pressure and psychiatric readmission may provide insight into understanding the common biological mechanisms underpinning CVDs, and later psychiatric relapse.

Our study provided the evidence of cardiovascular metabolic risk factors measurement, particularly HDL or BP, as the risk predictors of psychiatric readmission among patients with SMI. Therefore, any treatment to monitor the serum lipid and blood pressure would be beneficial to minimize the psychiatric illness burden such as reducing the risks of psychiatric admission. Indeed, it was recently reported that drugs in common use for metabolic health problems such as statins, calcium channel antagonists and metformin were associated with reduced rates of psychiatric admission and self-harm in individuals with SMI [53]. Given the massive illness burden of SMI, future randomized controlled studies are needed to validate the impact of the CVD risk factors screening and treatment during in-hospitalization period on subsequent psychiatric readmissions.

Our study is limited by the retrospective study design. Psychiatric hospitalization is an important means of stabilizing deteriorating psychiatric conditions, re-establishing discontinued regimen of prescribed medication and offering help to transit individuals to outpatient and community-based mental health services. Many individuals with SMI experience multiple psychiatric readmissions [5]. A number of factors have been proposed to be associated with psychiatric readmission among patients with SMI including the patients' previous number of hospitalization, which had been consistently reported to be the highest risk factor for readmission $[54,55]$ and the post-discharge factors, such as poor social support [56]. Therefore, the screening of cardiovascular metabolic risk factors at or before admission and after patients had been discharged from hospital might overstate the importance of monitoring the cardiovascular metabolic risk factors while the patient was in hospital, although those unmeasured confounders beyond the in-hospitalization period would be unlikely to fully explain our findings. In addition, we didn't collect other CVD related risk factors during hospitalization period such as smoking, drinking status and the severity of psychiatric symptoms. The latter was highly associated with the risks of psychiatric readmission which could be attributed to symptoms related drug prescription such as clozapine.

In summary, in-hospital poor measurement of cardiovascular metabolic risk factors was found to be associated with increased risks of psychiatric readmission among patients with SMI. Our finding implies that the medical professionals including both psychiatrists and family physicians in mental hospital may need to be more active in the screening and monitoring of CVD risk factors for in-hospital patients with SMI. Moreover, the observed association between components of cardiovascular metabolic risk factors with psychiatric readmission indicated that those CVD risk factors, such as blood lipid and blood pressure, could be new targets of therapeutic intervention to improve psychiatric care.

\section{Abbreviations \\ SMI: Severe mental illness; MDD: Major depression disorder; CVD: Cardiovas- cular disease; DM: Diabetes mellitus; FGlu: Fasting blood glucose; HbA1C: Hemoglobin A1C; SBP: Systolic blood pressure; DBP: Diastolic blood pressure; BMI: Body mass index; EHR: Electronic health record; ECT: Electroconvulsive therapy; HDL: High density lipoprotein; LDL: Low density lipoprotein; SD: Standard deviation; HR: Hazard risk; Cl: Confidence interval.}

\section{Supplementary Information}

The online version contains supplementary material available at https://doi. org/10.1186/s12888-022-03704-w.

Additional file 1: Supplementary Table 1. Group of diagnosis.

\section{Acknowledgements}

We would like to thank A/Prof Mythily Subramaniam and Prof Siow Ann Chong for their guidance and contributions to the conceptualization and inputs on the analysis of the data.

\section{Authors' contributions}

XWT, DF formulated the research questions; XWT, ESL, DF designed the study; XWT, DF collected the data; XWT and PCT analysed the data; XWT, YWC, PCT wrote first draft of the article and all authors reviewed and approved the manuscript in current version.

\section{Funding}

This research did not receive any specific grant from funding agencies in the public, commercial, or not-for-profit sectors.

\section{Availability of data and materials}

The data that support the findings of this study is not publicly available and only accessible from the corresponding author (Dr Xiao Wei Tan xiaowei_tan@ imh.com.sg) on reasonable request via approval by the Institutional Research Review Committee and the National Healthcare Group Domain Specific Review Board. 


\section{Declarations}

\section{Ethics approval and consent to participate}

Ethical approval to conduct the study was obtained from the Institute of Mental Health Institutional Research Review Committee (IRRC) and the National Healthcare Group Domain Specific Review Board with patient's informed consent waived.

\section{Consent for publication}

Not applicable.

\section{Competing interests}

None.

\section{Author details}

'Department of Mood and Anxiety, Institute of Mental Health, Buangkok Green Medical Park, 10 Buangkok View, Singapore 539747, Singapore. ${ }^{2}$ Medical Care Service, Institute of Mental Health, Singapore 539747, Singapore. ${ }^{3}$ Clinical Research Unit, National Healthcare Group Polyclinics, Singapore 138543, Singapore. ${ }^{4}$ Lee Kong Chian School of Medicine, Nanyang Technology University of Singapore, Singapore 308232, Singapore. ${ }^{5}$ Duke-NUS Graduate Medical School, Singapore 169857, Singapore.

Received: 5 August 2021 Accepted: 11 January 2022

Published online: 18 January 2022

\section{References:}

1. Jobe TH, Harrow M. Long-term outcome of patients with schizophrenia: a review. Can J Psychiatry. 2005;50(14):892-900.

2. Leverich GS, Post RM, Keck PE Jr, et al. The poor prognosis of childhoodonset bipolar disorder. J Pediatr. 2007;150(5):485-90.

3. Verduijn J, Verhoeven JE, Milaneschi Y, et al. Reconsidering the prognosis of major depressive disorder across diagnostic boundaries: full recovery is the exception rather than the rule. BMC medicine. 2017;15(1):215.

4. Hensing G, Wahlstrom R. Swedish Council on Technology Assessment in Health Care (SBU). Chapter 7. Sickness absence and psychiatric disorders. Scand J Public Health Suppl. 2004:63:152-80.

5. Madi N, Zhao H, Li JF. Hospital readmissions for patients with mental illness in Canada. Healthc Q. 2007:10(2):30-2.

6. Cunningham R, Sarfati D, Peterson D, Stanley J, Collings S. Premature mortality in adults using New Zealand psychiatric services. N Z Med J. 2014:127(1394):31-41.

7. Grigoletti L, Perini G, Rossi A, et al. Mortality and cause of death among psychiatric patients: a 20-year case-register study in an area with a community-based system of care. Psychol Med. 2009;39(11):1875-84.

8. Kisely S, Smith M, Lawrence D, Maaten S. Mortality in individuals who have had psychiatric treatment: population-based study in Nova Scotia. The British journal of psychiatry : the journal of mental science. 2005;187:552-8.

9. Lawrence D, Hancock KJ, Kisely S. The gap in life expectancy from preventable physical illness in psychiatric patients in Western Australia: retrospective analysis of population based registers. BMJ. 2013;346:f2539.

10. Capasso RM, Lineberry TW, Bostwick JM, Decker PA, St SJ. Mortality in schizophrenia and schizoaffective disorder: an Olmsted County, Minnesota cohort: 1950-2005. Schizophr Res. 2008:98(1-3):287-94.

11. Osby U, Correia N, Brandt L, Ekbom A, Sparen P. Time trends in schizophrenia mortality in Stockholm county, Sweden: cohort study. BMJ. 2000;321(7259):483-4

12. Robson D, Gray R. Serious mental illness and physical health problems: a discussion paper. Int J Nurs Stud. 2007;44(3):457-66.

13. Saha $S$, Chant D, McGrath J. A systematic review of mortality in schizophrenia: is the differential mortality gap worsening over time? Arch Gen Psychiatry. 2007;64(10):1123-31.

14. Perez-Pinar M, Mathur R, Foguet Q, Ayis S, Robson J, Ayerbe L. Cardiovascular risk factors among patients with schizophrenia, bipolar, depressive, anxiety, and personality disorders. European psychiatry : the journal of the Association of European Psychiatrists. 2016;35:8-15.
15. Deh M, Correll CU, Bobes J, et al. Physical illness in patients with severe mental disorders. I. Prevalence, impact of medications and disparities in health care. World psychiatry: official journal of the World Psychiatric Association (WPA). 2011;10(1):52-77.

16. Baptista T, De Mendoza S, Beaulieu S, Bermudez A, Martinez M. The metabolic syndrome during atypical antipsychotic drug treatment: mechanisms and management. Metabolic syndrome and related disorders Fall. 2004;2(4):290-307.

17. Kroeze WK, Hufeisen SJ, Popadak BA, et al. H1-histamine receptor affinity predicts short-term weight gain for typical and atypical antipsychotic drugs. Neuropsychopharmacology : official publication of the American College of Neuropsychopharmacology. 2003;28(3):519-26.

18. Regenold WT, Thapar RK, Marano C, Gavirneni S, Kondapavuluru PV. Increased prevalence of type 2 diabetes mellitus among psychiatric inpatients with bipolar I affective and schizoaffective disorders independent of psychotropic drug use. J Affect Disord. 2002;70(1):19-26.

19. De Hert M, van Winkel R, Silic A, Van Eyck D, Peuskens J. Physical health management in psychiatric settings. European psychiatry : the journal of the Association of European Psychiatrists. 2010;25(Suppl 2):S22-28.

20. Heald A, Montejo AL, Millar H, De Hert M, McCrae J, Correll CU. Management of physical health in patients with schizophrenia: practical recommendations. European psychiatry : the journal of the Association of European Psychiatrists. 2010;25(Suppl 2):S41-45.

21. Maj M. Physical health care in persons with severe mental illness: a public health and ethical priority. World psychiatry : official journal of the World Psychiatric Association (WPA). 2009;8(1):1-2.

22. Saravane $D$, Feve $B$, Frances $Y$, et al. Drawing up guidelines for the attendance of physical health of patients with severe mental illness. L'Encephale. 2009;35(4):330-9.

23. American Diabetes Association; American Psychiatric Association; American Association of Clinical Endocrinologists; North American Association for the Study of Obesity. Consensus development conference on antipsychotic drugs and obesity and diabetes. J Clin Psychiatry. 2004. 65;2:267-272.

24. De Hert M, Detraux J, van Winkel R, Yu W, Correll CU. Metabolic and cardiovascular adverse effects associated with antipsychotic drugs. Nat Rev Endocrinol. 2011;8(2):114-26.

25. Druss BG, Marcus SC, Campbell J, et al. Medical services for clients in community mental health centers: results from a national survey. Psychiatr Serv. 2008;59(8):917-20.

26. Parameswaran SG, Chang C, Swenson AK, Shumway M, Olfson M, Mangurian CV. Roles in and barriers to metabolic screening for people taking antipsychotic medications: a survey of psychiatrists. Schizophr Res. 2013;143(2-3):395-6.

27. Chong SA, Mythily, Lum A, Chan YH, McGorry P. Determinants of duration of untreated psychosis and the pathway to care in Singapore. Int J Soc Psychiatry. 2005;51(1):55-62.

28. Fleury MJ, Bamvita JM, Farand L, Aubé D, Fournier L, Lesage A. GP group profiles and involvement in mental health care. J Eval Clin Pract. 2012;18(2):396-403.

29. Lum AW, Kwok KW, Chong SA. Providing integrated mental health services in the Singapore primary care setting-the general practitioner psychiatric programme experience. Ann Acad Med Singapore. 2008;37(2):128-31.

30. Ahmad FS, Metlay JP, Barg FK, Henderson RR, Werner RM. Identifying hospital organizational strategies to reduce readmissions. Am J Med Qual. 2013;28(4):278-85.

31. Ahmedani BK, Solberg LI, Copeland LA, et al. Psychiatric comorbidity and 30-day readmissions after hospitalization for heart failure, AMI, and pneumonia. Psychiatr Serv. 2015;66(2):134-40.

32. Pederson $J \mathrm{~L}$, Warkentin LM, Majumdar SR, McAlister FA. Depressive symptoms are associated with higher rates of readmission or mortality after medical hospitalization: A systematic review and meta-analysis. J Hosp Med. 2016:11(5):373-80.

33 Shameer K, Perez-Rodriguez MM, Bachar R, et al. Pharmacological risk factors associated with hospital readmission rates in a psychiatric cohort identified using prescriptome data mining. BMC. 2018;18(Suppl 3):79.

34. Sprah L, Dernovsek MZ, Wahlbeck K, Haaramo P. Psychiatric readmissions and their association with physical comorbidity: a systematic literature review. BMC psychiatry. 2017;17(1):2. 
35 Mo Health. Screening for cardiovascular disease and risk factors, vol. 1. Singapore: Mministry of Health; 2011.

36. Essock SM, Covell NH, Leckman-Westin E, et al. Identifying clinically questionable psychotropic prescribing practices for medicaid recipients in new york state. Psychiatr Serv. 2009;60(12):1595-602.

37. Haupt DW, Rosenblatt LC, Kim E, Baker RA, Whitehead R, Newcomer JW. Prevalence and predictors of lipid and glucose monitoring in commercially insured patients treated with second-generation antipsychotic agents. Am J Psychiatry. 2009;166(3):345-53.

38. Morrato EH, Druss B, Hartung DM, et al. Metabolic testing rates in 3 state Medicaid programs after FDA warnings and ADA/APA recommendations for second-generation antipsychotic drugs. Arch Gen Psychiatry. 2010;67(1):17-24.

39. Baller JB, McGinty EE, Azrin ST, Juliano-Bult D, Daumit GL. Screening for cardiovascular risk factors in adults with serious mental illness: a review of the evidence. BMC psychiatry. 2015;15(1):55.

40. Druss BG, von Esenwein SA, Compton MT, Rask KJ, Zhao L, Parker RM. A randomized trial of medical care management for community mental health settings: the Primary Care Access, Referral, and Evaluation (PCARE) study. Am J Psychiatry. 2010;167(2):151-9.

41. Druss BG, von Esenwein SA, Glick GE, et al. Randomized Trial of an Integrated Behavioral Health Home: The Health Outcomes Management and Evaluation (HOME) Study. Am J Psychiatry. 2017;174(3):246-55.

42. Mark TL, Tomic KS, Kowlessar N, Chu BC, Vandivort-Warren R, Smith S. Hospital readmission among medicaid patients with an index hospitalization for mental and/or substance use disorder. J Behav Health Serv Res. 2013;40(2):207-21.

43. Irmiter C, McCarthy JF, Barry KL, Soliman S, Blow FC. Reinstitutionalization following psychiatric discharge among VA patients with serious mental illness: a national longitudinal study. Psychiatry Q. 2007;78(4):279-86.

44. Olusi SO, Fido AA. Serum lipid concentrations in patients with major depressive disorder. Biol Psychiat. 1996;40(11):1128-31.

45. Sadeghi M, Roohafza H, Afshar $H$, et al. Relationship between depression and apolipoproteins A and B: a case-control study. Clinics (Sao Paulo, Brazil). 2011;66(1):113-7.

46. Huang TL, Chen JF. Serum lipid profiles and schizophrenia: effects of conventional or atypical antipsychotic drugs in Taiwan. Schizophr Res 2005;80(1):55-9.

47. Hildrum B, Mykletun A, Holmen J, Dahl AA. Effect of anxiety and depression on blood pressure: 11-year longitudinal population study. The British journal of psychiatry : the journal of mental science. 2008;193(2):108-13.

48. Hildrum B, Mykletun A, Stordal E, Bjelland I, Dahl AA, Holmen J. Association of low blood pressure with anxiety and depression: the Nord-Trondelag Health Study. J Epidemiol Community Health. 2007;61(1):53-8.

49. Rutledge $T$, Hogan BE. A quantitative review of prospective evidence linking psychological factors with hypertension development. Psychosomatic medicine Sep-Oct. 2002;64(5):758-66.

50. Scherrer JF, Xian H, Bucholz KK, et al. A twin study of depression symptoms, hypertension, and heart disease in middle-aged men. Psychosomatic medicine Jul-Aug. 2003;65(4):548-57.

51. Licht CM, de Geus EJ, Seldenrijk A, et al. Depression is associated with decreased blood pressure, but antidepressant use increases the risk for hypertension. Hypertension (Dallas, Tex:1979). 2009;53(4):631-8.

52. Morra LF, Strauss GP. Severity of hypertension predicts the generalized neurocognitive deficit in schizophrenia. Schizophr Res. 2016;176(2-3):527-8.

53. Hayes JF, Lundin A, Wicks S, et al. Association of Hydroxylmethyl Glutaryl Coenzyme A Reductase Inhibitors, L-Type Calcium Channel Antagonists, and Biguanides With Rates of Psychiatric Hospitalization and Self-Harm in Individuals With Serious Mental IIIness. JAMA Psychiat. 2019;76(4):382-90.

54. Donisi V, Tedeschi F, Salazzari D, Amaddeo F. Pre- and post-discharge factors influencing early readmission to acute psychiatric wards: implications for quality-of-care indicators in psychiatry. General hospital psychiatry Mar-Apr. 2016;39:53-8.

55. Donisi V, Tedeschi F, Wahlbeck K, Haaramo P, Amaddeo F. Pre-discharge factors predicting readmissions of psychiatric patients: a systematic review of the literature. BMC psychiatry. 2016;16(1):449.

56. Guzman-Parra J, Moreno-Kustner B, Rivas F, Alba-Vallejo M, HernandezPedrosa J, Mayoral-Cleries F. Needs, Perceived Support, and Hospital Readmissions in Patients with Severe Mental IIIness. Community Ment Health J. 2018;54(2):189-96.

\section{Publisher's Note}

Springer Nature remains neutral with regard to jurisdictional claims in published maps and institutional affiliations.
Ready to submit your research? Choose BMC and benefit from:

- fast, convenient online submission

- thorough peer review by experienced researchers in your field

- rapid publication on acceptance

- support for research data, including large and complex data types

- gold Open Access which fosters wider collaboration and increased citations

- maximum visibility for your research: over $100 \mathrm{M}$ website views per year

At BMC, research is always in progress.

Learn more biomedcentral.com/submissions 